\title{
Reflections on the Distinctiveness of Public Administration as a Discipline
}

Arthur Ringeling

\begin{abstract}
The paper discusses some issues which are relevant for the further development of Public Administration as an academic discipline. Firstly, there is reason to be skeptical about universal features of this discipline, as there is much variety in the practice of Public Administration around the world. Secondly, the orientation of Public Administration towards public values is emphasized. Thirdly, the relevance of the concept of a democratic Rechtsstaat as a starting point for the design of Public Administration content must be stressed. And finally, the paper discusses institutional issues, e.g. the question if education of future civil servants should take place at government-controlled schools or within universities.
\end{abstract}

\section{Introduction}

This contribution originated as a comment on a presentation of Christoph Reichard at the Trans-European Dialogue in Potsdam, February 2013 (Reichard 2013). It offered me the opportunity to stress a number of points that I think are important for the development of Public Administration. The first is that we have to be careful when speaking about global or universal developments in our field. We can at the same time see variety in the practice of public administration and in our discipline. The second point is that Public Administration is not only about the management of implementation, but also about public values. The third point is that there is a normative starting point for that discussion as well as for the way governments implement; this starting point is the democratic Rechtsstaat and students of Public Administration should take that into account. The fourth point is that our students should be educated in such a way that they know that public administration is a unique phenomenon. And the fifth point refers to the question: where should the civil servants of the future be educated, in schools controlled by the state, or should 
they have the possibility to choose between different academic institutions? Consider these five points as a contribution to an ongoing discussion.

\section{Global Developments?}

A number of authors indicated what happened in public administration in the last decades as an international trend. Hood (1991) was one of the first in pointing to what he described as "... a public management for all seasons". The thinking in terms of a universal truth in Public Administration was strongly stimulated by this Anglo-Saxon model of Public Administration. In particular in the English-speaking countries the model became popular. And afterwards the same developments could be seen in many other countries. Kettl speaks of a global management revolution:

Since the 1980s a global reform movement in public management has been vigorously under way. The movement has been global in two senses. First, it had spread around the world to nations including Mongolia (sic AR), Sweden, New Zealand, and the United States. Second, it had been sweeping in scope. Governments have used management reform to reshape the role of the state, and its relationship with citizens. Some nations, such as the United States, have been inveterate reformers (Kettl 2000, 1).

Frederickson and Smith $(2003,214)$ characterize New Public Management as a global public-management reform movement that has redefined the relationships between government and society. Both are statements with far-reaching consequences, as Schultz (2011) makes clear. Soon, Dwivedi and William $(2011,31)$ write:
... the NPM movement became so intrusive that only a very few countries could remain immune from its reform agenda as the pressure for privatization, deregulation, contracting out, public- private partnerships, an emphasis on results and performance, and a focus on service quality and consumer orientation became overwhelming for both the developed and developing world.

We are inclined to speak of global developments. But how global is global when you read, for instance, Christoph Reichard's and Manfred Röber's book (2012) about the developments in public administration in Germany? The "Juristen-Monopol" still exists there, perhaps a little on the way back, but nevertheless. That brings us to the question of how important regional and national developments are and how strong regional and national cultures are. And to what extent do we have to take that into account when we, as representatives of Public Administration, want to say meaningful things? Because the globalization movement has a stringent normative implication: the global trend is one to follow. And those who do not do that are lagging behind. I have serious doubts. 
Correctly, Reichard emphasizes in his paper the importance of international exchange. And how much did we enjoy it. All those students that, with the help of the former Erasmus and Leonardo programs, went from one country to another, returning better than when they left and as the vanguard of a generation of Europeans. It is so stimulating, so useful. You learn from it, it brings you new insights, it can be a reason to put into perspective phenomena that take place in your own country. And when it is about renewal, all those countries, states, provinces, districts and municipalities try to find their own solutions.

Here my reasoning already begins to take a turn, because the fact that political entities experiment has a value in itself. It can be considered a part of the democratic experience, and it is not excluded that some governing body will come with a better solution than others. Whatever the attractiveness of the individual experience was, the institutional story is a different one, because internationalization has its limits. It is the important lesson of Pollitt and Bouckaert (2011) in their study of how different countries in the world made their own national versions of New Public Management. It is to some extent dubious whether you can transplant a solution found in one political entity to another. This message was written in headlines in developments studies. We also learned it from comparative research. How attractive it is to do it, how complicated it is to do it well. Already the translation of terms is a quest, not to speak of the culture behind them. We shall not forget these lessons when we go international, and even more when we talk about global developments.

\section{Public Sector Values}

The distinction between politics and administration has its history in Public Administration. With Waldo (1948) we may say that it is history. The idea that politics sets the rules and that the administration implements them does not give an adequate picture of reality. That politics is the world of values and administration the world of facts is a caricature of what we can see in the public sphere, not only because politicians paid much attention to the way policies should be implemented. Also we learned from implementation research that executing a policy is constantly a process of making rules. And we learned that an administration without values creates its own monster.

But what have we done with that insight? And what do we do next? The consequence that I recognize is that values are not the exclusive concern of politicians, even not of politics. This is not a new insight because there have always been values that were central in the discussion of the practice and the discipline of public administration. Effectiveness and efficiency were and are such dominant values. But after the politics-administration distinction was a relic of the past, the value discussion became more open. New public vales became part of the discourse in Public Administration. And as Larat (2013) makes clear, values encompass more 
than technical skills, but also aptitudes and reflexes allowing public officials to fulfill a public mission in a value-loaded way.

A number of values became part of the discussion. From the seventies on, the democratic character of public administration was stressed (cf. Marini 1971). Frederickson (1997) suggests social equity and Rawls (2001), close to it, fairness. If the public sector is about fairness, and I think it is, what are the consequences of that insight? First, that the public sector has more to serve than efficiency. It is even questionable how important that value is in the public realm. Governments are not there to be efficient. Not in the strict sense of cost-efficiency. Because according to that standard, governments are doing many things that are all but efficient. Perhaps we may ask them to be socially efficient. But that concept is a quagmire, because calculations using that value are complicated and in no time part of a political discussion. Knowing that, we can have a moderate reaction when it is proved that governments are acting relatively ineffectively or inefficiently. Procedural fairness is at least as important as an example of administrative values (see Luhmann 1969).

We can argue that governments have to take more values into account then legality. But if they do not take that value seriously enough, our reaction is quite different. Governmental acts that are illegal are unacceptable. We think so, because the democratic Rechtsstaat is part of our cultural heritage and central in judging what governments can and cannot do. We have organized an extended control system for it, called courts, judges, ombudsmen etc. All these institutional arrangements stress the central importance of the legality value.

"Unacceptable" is a qualification that we are not inclined to use so quickly when a certain governmental policy is inefficient. From the point of view of the market, most policies are. We do not want to use this qualification either when certain decisions are not legitimate. There are always decisions where some are in favor and others object. When the opposition is considerable, when it concerns very crucial decisions or when it is the same group that always loses the political battle, the political regime will potentially have a problem. But in other circumstances, it is more a fact of life.

I hope to have illustrated that the values mentioned have different weight and different effects. They are not of the same importance. Values never have all been of the same importance during history. One value is not interchangeable with the other. But perhaps in modern Public Administration we made the wrong choice when we thought effectiveness and efficiency were the only relevant ones (Ringeling 2004). The position of legality is a very special one, not only legality according to the rules, how important they are, but above all according to the principles of law (Dworkin 2011). It is the way legality can offer us content to fairness. 


\section{An Orientation on Law}

There is a long tradition in the law programs to broaden their scope. It could also be seen in specializations directing to business, where economics became an important field of study. And penal law studies also got attention for the social and psychological backgrounds of criminal activities. So criminology became a part of the law program. More recent is the attention to management. It is easy to explain such a tendency: real-world problems are not organized according to disciplinary boundaries. In practice, societal problems have little to do with our academic division of labor. Law programs understood that. This insight was a stimulus for the establishment of Public Administration in the past, for its multi- and interdisciplinary character (cf. Raadschelders 2011). In the Continental tradition it constituted itself as part of the Law program, with close ties to public law.

If this tendency to broaden the scope of a program is acknowledged, should that not initiate another development as well? Perhaps management alone is not enough as an education for the public sector. Should students not learn what it means to operate in the public sector? Do they not have to know the special character of it? Need they not be confronted with the crucial significance of the democratic Rechtsstaat? Is it not the consequence that they should have knowledge of the importance of law, as well? Not so much the detailed rules of administrative law, because lawyers do know that much better. Above all should they not have knowledge about the principles of law, the fundaments on which our type of state is build? Rosenbloom (2003) argued that point of view in the US. And we can understand it, because the US tradition of Public Administration, as this author remarks, is at some distance from law. But we from the Continental tradition seem to have lost the insight that was so fashionable, I am inclined to say normal, in the past. The relationship between Public Administration and Public Law that originally was so intense, changed dramatically. Nowadays we have Public Administration and Public Management programs that do not pay any attention to the principles of law. Did the so-called globalizing of Public Administration cause us to forgot crucial insights for our field of study?

Legality does not have to be considered an instrument, nor a toy for law people. On the contrary, legality is fundamental for our kind of political-administrative system. The Rechtsstaat is founded on the idea that the state is bound to laws and rules (Witteveen 2000, 203). That idea is a kind of normative horizon in which meaningful political and juridical actions are possible. Key concepts connected to the democratic Rechtsstaat are, according to Witteveen: representation, public interest, responsibility, separation of powers and checks and balances, citizenship, public morality, responsiveness and mediation between public organizations and citizens. Some authors add to this already impressive list fundamental rights and the protection of minorities. So the concept is not without consequences for the 
governance of the state. The executive power gets no more power than necessary for the execution of laws and now and then even less.

The democratic Rechtsstaat is a construction. Perhaps to some people, it is an ideological construction, but a construction nevertheless. The Rechtsstaat is considered a democratic construction. Legality refers to rule-giving. And rules do not come into being without the cooperation of representative bodies. The rule of law is in the heart of the organization of the modern state. It determines the actions of government officials and citizens.

Should programs directed to a public-administration education not include ideas about the democratic Rechtsstaat? There are several reasons for the position that they must. The first I mentioned already, our European past. The second is that we seem to have developed too much in an instrumental way. If the law does not fit our purpose, our reflex in public-policy-making is to change it. As a consequence, the state is becoming more and more unpredictable in its behavior. It contradicts easily what it said the day before. By doing so, it runs the chance of undermining its own legitimacy. The third reason is that students of Public Administration should understand the way law people think and argue. Also they should understand the thinking of graduates from other relevant disciplines.

\section{Public Administration as a Unique Phenomenon}

A Public Administration program has to make clear that it is concentrated on a specific material object. And that the object is unique. Governments, or if you prefer states, are not like any other organization. I have six reasons for saying so (cf. Ringeling 2004).

The first reason is the special character of the tasks of the public sector. Governmental tasks in part concern problems that other sectors of society are unable or unwilling to solve, often because these problems are hard to solve. The basic function of government is, as David Easton (1971) put it, the authoritative allocation of values in and on behalf of a society. So, conflicting values are typically what public administration has to handle. Conflicts about public values in society are transformed into conflicts within the public sector and into temporary compromises between these values. That is the reason why procedures of decision-making within the public sector are of great importance and why fairness in the procedures and in the results is necessary. The consideration and allocation of values have to take place in a way by which societal conflicts are diminished instead of stimulated. Our evaluation of public performance is inadequate when these procedural requirements are not taken into account. There is more to evaluate than the delivery of goods and services. Not only the allocation of values is important in the public sphere, but also the way in which this allocation takes place. 
As a consequence, the products of government, if we accept the term for a moment, have a strongly idealistic character and are mostly controversial, before as well as after public decisions have been made. As a consequence government not only allocates, but also divides people. It makes choices or compromises between competing values. These choices create winners and losers, but neither of these groups will be satisfied with the decision - the losers because they lost and the winners because they got less than they wanted. Moreover, most products of government are not consumed voluntarily. Circumstances and the characteristics of the tasks force people to make use of government supply. The metaphor of the citizen as a client of governmental organizations is an ill-conceived one. For most people there is a strong drive not to become a client of the state.

The second reason is that governments do not have a free choice which instruments they use. In real life a toolbox (see Hood 1983) rarely exists. What is more, the effects of instruments are often limited. Society is not a passive object but an active subject. It has instruments of its own, with which it reacts to government intervention. The possibilities of a government are further limited when it has to regulate its actions. Regulation diminishes the flexibility and the precision of its interventions.

Government actions, as a consequence, are less adequate than the situation asks for. In short, government has a limited number of instruments, instruments moreover with limited effects, which, taking into account the circumstances in which they have to be used, are sub-optimal per definition. Only an authoritarian state can refrain from considerations about the means it applies.

Third, with the greater intensity of government intervention, conflicts between public-sector organizations also became a more common phenomenon. When the task of government is to allocate values, it decides on societal conflicts. Government organizations handle value conflicts that exist in society in one way or another. The conflict is transferred from the private to the public sector, and in the public sector the values at stake mostly are allocated to different organizations. In the public sector, the conflict continues to exist, but in a mitigated way. It is represented by political movements, but also by different governmental organizations. As a consequence, the public sector is a divided house.

A fourth reason is that what governments are able to do depends to an important extent on organizations other than those from the public sector. Public administration is a strange organization in the sense that it cannot determine its own goals, its own tasks or even its own organization. It is subject to the interventions of its political environment, in its policy-making as well as in its implementation. Not all these political interventions are very well implementable or coordinated.

Moreover governmental organizations depend strongly on their environment in the implementation of policy. First, an important part of public tasks, like education, public health, housing or welfare, is not implemented by public organizations, 
but by private organizations. Without the collaboration of societal actors, organizations or citizens, the realization of public tasks is a mission impossible. Governance is the term that was coined for it. Business firms, other private organizations or citizens are often the implementers of governmental programs. And they, involuntary clients as they are, have to be inclined to obey the intentions of the interventions.

The fifth reason is that government is not a business. It is popular to suggest that government should be run as a business. But it is an advice that is founded on a serious mistake. In methodological terms, it is the fallacy of the wrong level. The comparison is only correct when government is considered one organization, but it is not. Sure, there are other ways to compare public and private organizations. But the attempt to compare the achievements of individual public and private organizations was a relatively successful one. John Donahue (1989) offered us the useful insight that the circumstances in which organizations operate constitute a much more important variable for their performance than their status according to the law.

The sixth reason offers the opportunity to develop another view on public policy. It is no longer goals and means but direct material effects that are prominent. It is necessary to have an eye for the symbolic character of what governments do. In this approach public policy is a world of symbols, myths, taboos, metaphors, rituals and rhetoric. Problems are temporarily shared views on reality. Solutions for these problems are not related as the best means for given ends, but strengthen certain political coalitions and make others weaker. Public policy can implicate a temporary solution for societal conflicts or a transport to other, better manageable arenas. In this view, inspired by Edelman (1977), it is not important what the effects of government policy really are. It is doubtful whether they can be established at all. Decisive is what the actors think they are.

The public sector not only has to be evaluated for its deliverance of material goods and services. The processes in the public sector themselves represent certain values. The games played in the public sector constitute a part of the political spectacle. These games do not justify themselves, they are played for the fun of it. These games are directed at the transformation of opposing values held by societal actors regarding authoritative and apparently rational decisions of public organizations. Diversity of values, and not unity, is the core of the public sector.

Public Administration programs have to pay attention to the specific character of the public sector. They have to take into account that a managerial approach to government is a partial one. Public Administration programs are not the public variant of MBA programs. They have to pay attention to the normative, value-laden character of the public sphere. What is needed in Public Administration is an open eye for public values (cf. Moore 1995), for the significance of the public culture and the public sector. 


\section{Training for the Public Sector}

Who should decide about the persons to be educated for the public sector, and who should decide about the program for that education? It is clear that we have quite different situations all over the world. The most important writer of the Dutch constitution once formulated the principle that governments should not become judges on science and art. They should not judge what people at universities do and the way they come to their insights. Let me formulate it somewhat more down to earth: it is undesirable for governments to play university. The question is to what extent that insight has played a leading role in educating for the public sector. In the US, apart from the military and some others, almost all people working in the public sector are trained in all kind of programs at generic universities. In contrast, in important parts of Europe, most public officials are trained in special governmental institutions, sometimes even organized on the departmental level. I like to make a few comments on the latter situation, although I know that I am on thin ice.

Governmental training institutions have their undeniable advantages. They are particularly strong in the reproduction of the governmental, even departmental or local culture. But culture is a double-edged sword: it unites as well as it divides. It brings together as well as it keeps apart. It stabilizes internal strives and relations as well as it excludes intentions and developments. It can bring about the bridge between the school and society becoming more and more narrow. The school can lose contact with its environment. That can be even more so when the national school has a monopoly on governmental positions.

The governmental school can also easily become a target for institutionalized politics. In some countries, high government officials and high-ranking politicians come from the same school. In others, the school becomes an object of political struggle, because they are part of the power base. What are the considerations in member states of the European Union to educate military and police officers and civil servants at the same organization? Is it to enlarge freedom of thought on the academic level or to strengthen control of public-educational institutions? It turns out that there are two sides to acculturation. Administration under these circumstances is politics, and for the training of public officials the same is true. Program changes are sometimes the result of the change of regimes. Also university-based programs have their relationships with government departments and with politicians. But in most cases these relationships are at a much greater distance. There is less organizational and power dependency. And those who have a preference for another program are free in their choice.

Which values will rule in such a form of education? Is it the freedom of thought and speech that is characteristic of academic institutions? Is there the possibility to say "no" to those in power? Is it possible to do research on the quality of the clothes of the emperor? Or is the school there to speak the words of its masters, to prepare 
for implementation of government policy, right or wrong? Does the institution contribute to discipline the public sector? We should analyze the dominating values in the diverse institutional arrangements that have developed over time, not only in developing countries, but in the West and North as well, at state training schools as well as in university programs.

It will not be a surprise that I do not have much affinity for governmental organizations playing for university. Above all because the free exchange of different opinions and the deliberation about them is the foundation of the state I prefer. It implies a situation in which a diversity of institutions exists, with an agreeable level of competition. In each there are differences of insights. The education differs from program to program. But in one way or another, they shed light on the specificity of the public sector, they pay attention to the democratic Rechtsstaat as a crucial concept, they have attention for the application of ideas and insights in the sector and in society, in which intensive value discussions are a daily phenomenon and where exchange with other institutions, regionally, nationally, and internationally, is a highly valued experience. Those schools I would love, because they are good for the people attending them and for the public domain as a whole.

\section{References}

Donahue, John D. 1989. The Privatization Decision: Public Ends, Private Means. New York: Basic Books.

Dwivedi, O. P. and Gabriel William. 2011. "Public Administration: State of the Discipline." In O. P. Dwivedi (ed.). Public Administration in a Global Context: IASIA at 50. Brussels: Bruylant, 21-52.

Dworkin, Ronald. 2011. Justice for Hedgehogs. Cambridge, Mass: Belknap Press.

Easton, David. 1971 [1953]. The Political System; An Inquiry into the State of Political Science. New York: A. Knopf.

Edelman, Murray. 1977. Political Language: Words That Succeed and Policies That Fail. New York: Academic Press.

Frederickson, H. George. 1997. The Spirit of Public Administration. San Francisco: Jossey-Bass.

Frederickson, H. George and Kevin B. Smith. 2003. The Public Administration Theory Primer. Boulder, Col: Westview.

Hood, Christopher. 1991. "A Public Management for all Seasons?" Public Administration 69, 3-19.

Hood, Christopher C. 1983. The Tools of Government. London/Basingstoke: MacMillan Press. 
Kettl, Donald, 2000, The Global Public Management Revolution: A Report on the Transformation of Governance, Washington. D.C.: Brookings Institution Press.

Larat, Fabrice. 2013. “What Part Do Virtues Play in Public Administration?” Paper presented at the $6^{\text {th }}$ Trans-European Dialogue, 6-8 February 2013, Potsdam, Germany.

Luhmann, Niklas. 1969. Legitimation durch Verfahren. Neuwied: Luchterhand.

Marini, Frank. 1971. Towards a New Public Administration: The Minnowbrook Perspective. New York: Chandler.

Moore, Mark H. 1995. Creating Public Value: Strategic Management in Government. Cambridge, Mass./London: Harvard University Press.

Pollitt, Christopher and Geert Bouckaert. 2011. Public Management Reform: A Comparative Analysis: New Public Management, Governance and the NewWeberian State. $3^{\text {rd }}$ edn. Oxford: Oxford University Press.

Raadschelders, Jos. 2011. Public Administration: The Interdisciplinary Study of Government. Oxford: Oxford University Press.

Rawls, John. 2001. Justice as Fairness: A Restatement. Cambridge, Mass: Belknap Press.

Reichard, Christoph. 2013. "Patterns of German Civil Service Education in a Comparative View." Presentation at the $6^{\text {th }}$ Trans-European Dialogue, 6-8 February 2013, Potsdam, Germany.

Reichard, Christoph, Manfred Röber. 2012. Ausbildung der Staatsdiener von morgen: Bestandsaufnahme, Reformtendenzen, Perspektiven. Berlin: Edition Sigma.

Ringeling, Arthur. 2004. Het imago van de overheid [The Image of Government]. Den Haag: Elsevier.

Rosenbloom, David H. 2003. Administrative Law for Public Managers. Boulder, Col: Westview.

Schultz, David. 2011. "The Crisis of Public Administration Theory in a Postglobal World." In Donald C. Menzel and Harvey L. White (eds). The State of Public Administration: Issues, Challenges, and Opportunities. New York/London: M. E. Sharpe, 453-463.

Waldo, Dwight. 1948. The Administrative State: A Study of the Political Theory of American Public Administration. New York: Ronald Press.

Witteveen, Willem. 2000. De denkbeeldige staat [The Imaginary State]. Amsterdam: Amsterdam University Press. 